\title{
Rainfall prediction based on the relationship between rainfall and EI Niño Southern Oscillation (ENSO)
}

\author{
Sumudu Adhikari ${ }^{1}$, Susanthi Liyanaarachchi ${ }^{1}$, Janaki Chandimala ${ }^{1}$, Badra K. Nawarathna ${ }^{1,2}$, \\ Ranmalee Bandara ${ }^{1}$, Zeenas Yahiya ${ }^{1}$ and Lareef Zubair ${ }^{1,3}$ \\ Foundation for Environment, Climate and Technology, Digana Village, Rajawella, Kandy. \\ Mahaweli Authority of Sri Lanka, HAO\&M Division, Digana Village, Rajawella, Kandy. \\ 3 International Research Institute for Climate and Society, The Earth Institute at Columbia University, Monell Building, Lamont Doherty Earth \\ Observatory, 61 Route 9w, Palisades, New York, USA.
}

\begin{abstract}
El Niño-Southern Oscillation (ENSO) is a dominant mechanism of global inter-annual climate variability. In this study, the relationship of ENSO to seasonal rainfall over 139 years is described. Ranking both, the seasonal Sri Lankan rainfall and its contemporaneous ENSO index show modest but significant association in January-March, May and JulyAugust and October-December periods. El Niño leads to wetter conditions during May, October-December and to drier conditions during January-March and July-August. Except for January-March the impacts of La Niña are inverse to that for El Niño. This relationship between rainfall and ENSO during October-December, January-March, July-August and May are statistically significant. This association can be used to predict rainfall during the planting phase and the harvesting phase of Maha (October-March), and during the harvest season of Yala (April-August). As ENSO predictions are regularly available, rainfall predictions can be provided 3-6 months in advance.
\end{abstract}

Keywords: Climate, El Niño, La Niña, Maha, Sri Lanka, Yala.

\section{INTRODUCTION}

El-Nino Southern Oscillation (ENSO) is a shift in the pattern of oceanic warming and atmospheric circulation centered in the Pacific Ocean with implications across the tropics and elsewhere that recurs typically 2 to 7 years apart. Anomalously warm sea surface temperatures in the equatorial Eastern Pacific is referred to as El Niño phase, and its cold analogue is referred to as La Niña. The influence of ENSO on the South Asian climate system varies with the season. The summer (June to
September) rainfall in northern India decreases with the El Niño, while in Sri Lanka and southernmost India rainfall increases from October to December ${ }^{3-5}$.

Several previous studies have analyzed ENSOrainfall relationships in Sri Lanka ${ }^{3,5-13}$. Many of these analyses have considered conventional meteorological seasons that are based on wind-directions (south-west monsoon, north-east monsoon and inter-monsoons) that range in duration from two to five months. These meteorological seasons do not align well with the traditional agricultural seasons ${ }^{1,14-16}$. The seasonal water resources and agricultural planning ("Kanna") meetings are conducted in March and September of each year and the rainfall predictions are needed at these meetings ${ }^{2}$.

The predictability of stream flow has been investigated using a principal component regression scheme in a cross-validated model taking the principal components of sea surface temperatures (SST) as the predictors ${ }^{17}$. This has resulted in skillful predictions for stream flow in the Yala (April-August) and Maha (October-March) seasons. The statistically significant relationship between rainfall and ENSO can be similarly exploited to predict rainfall. ENSO indices are best derived from SST. At present, several forecast centers issue skillful predictions of the seasonal evolution of tropical SST six months in advance ${ }^{18}$.

In this study the agricultural seasons and the annual cycle of ENSO influence have been considered 
to identify the seasons that have the highest utility and rainfall predictability (i.e. rainfall is enhanced in OctDec and May and declines in Jan-Mar and June to Aug). It must be noted, however, that from the point of view of the users of this information it is useful to quantify all ENSO based relationships even when they are weak, since they may have profound implications in their respective sectors. This paper describes the evaluation of the relationship between ENSO and rainfall in Sri Lanka through correlation analysis, composite analysis and ranked rainfall, and ENSO indices. A simple scheme for rainfall and skill assessment for all seasons in 2008 and 2009 is presented based on the association between ENSO and seasonal rainfall.

\section{METHODS AND MATERIALS}

Rainfall data: The monthly data for the period 1869 to 2007 from 16 widely distributed observatories were obtained from the Sri Lanka Department of Meteorology (Figure 1). A rainfall index for the entire island was constructed by averaging the monthly rainfall for these stations. In addition, regional rainfall indices were constructed by averaging the rainfall of stations falling within climatically homogenous regions that are described under the Regionalization in Climatology section. Basic statistics for rainfall are provided on a seasonal and regional basis (Table 1). Rainfall anomaly is the departure of rainfall from its (1869 to 2007) longterm average, and the ranked rainfall anomalies were used to construct tercile categories-wettest, normal and driest. These categories were used to compare ranked rainfall anomalies during the three ENSO phases.

ENSO index: An ENSO index in common use known as NINO3 had been constructed as the average SST anomaly for the eastern equatorial Pacific Ocean region of $\left(90^{\circ} \mathrm{W}\right.$ $-150{ }^{\circ} \mathrm{W}, 5^{\circ} \mathrm{S}$ to $\left.5^{\circ} \mathrm{N}\right){ }^{11}$. The ENSO phases are defined as: El Niño (NINO3 $\left.\geq 0.5^{\circ} \mathrm{C}\right)$, La Niña $\left(\mathrm{NINO} 3 \leq-0.5^{\circ} \mathrm{C}\right)$ and Neutral phases $\left(-0.5^{\circ}<\mathrm{NINO} 3<0.5^{\circ} \mathrm{C}\right){ }^{3-4}$.

Composite analysis: Composite rainfall was computed by averaging the monthly rainfall values when the particular ENSO phase (El Niño, Neutral or La Niña) prevailed (Figure2).

Correlation analysis: The Pearson correlation coefficient was used to identify relationships between ENSO indices and rainfall ${ }^{19}$. A correlation was taken to be significant when the no-correlation null hypothesis was exceeded with a probability of $95 \%$. Significance of correlation values were tested at $1 \%$ and $5 \%$ levels.

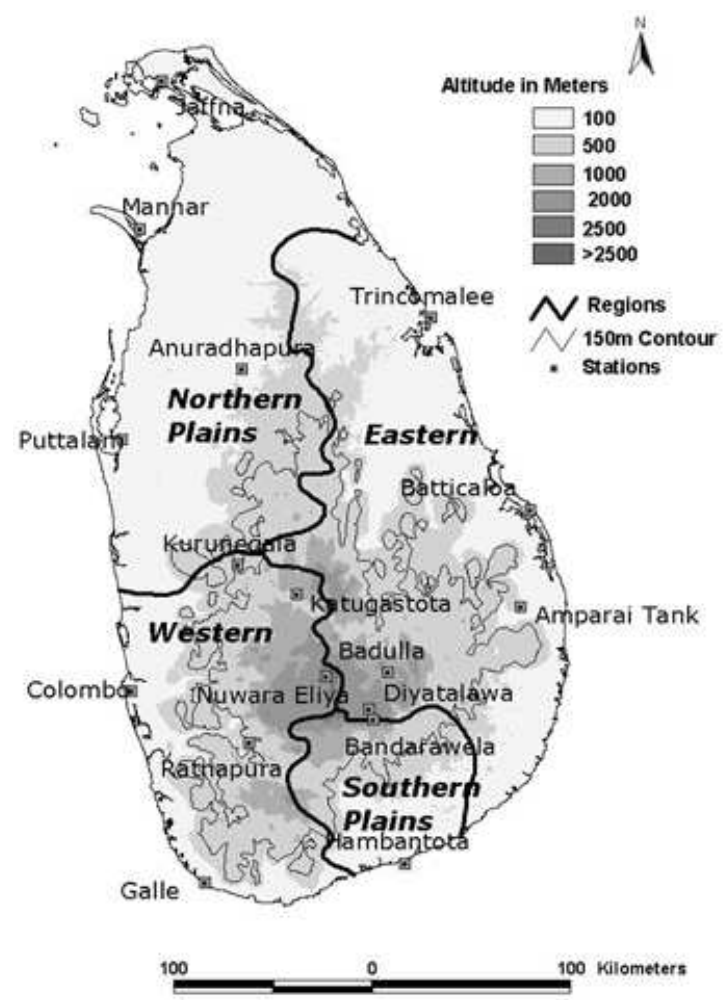

Figure 1: Topography, location of meteorological observatories, and regionalization for Sri Lanka. The $150 \mathrm{~m}$ contours that separate the low areas from the hilly areas are indicated. 


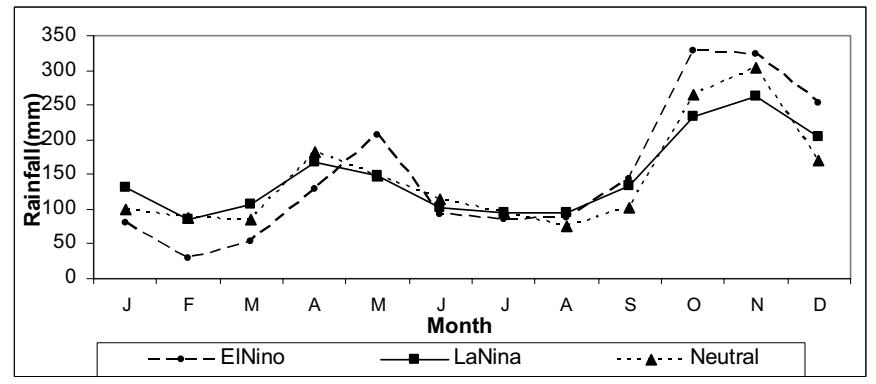

Figure 2: The composite rainfall climatology for all Sri Lanka during El Niño, La Niña and Neutral phases. The characters J to D stand for months from January to December.

Prediction scheme: Rainfall prediction scheme was carried out for all seasons in 2009 and 2010 based on ENSO relationship. Comparison between predicted and the actual rain fall which were segregated into three terciles "below-normal", "near-normal" and "abovenormal" are presented in Table 4 along with the prevailing ENSO phase.

Prediction skill assessment: Heidke skill scores are used to provide some measure of forecast quality when the predictions and corresponding observations are expressed in categories ${ }^{25}$. The Heidke score (S) is given by $\mathrm{S}=100(\mathrm{C}-\mathrm{E}) /(\mathrm{N}-\mathrm{E})$ where $\mathrm{C}$ is the number of forecasts; $\mathrm{E}$ is the number of correct forecasts expected by chance, and $\mathrm{N}$ is the total number of forecasts.

\section{Climatology:}

a) Mean annual cycle: The mean annual cycle of rainfall in Sri Lanka is bimodal ${ }^{20-21}$, with a major mode from October to December and a subsidiary mode from April to June (Figure 2). The October to December rainfall coincides with the commencement of the main cultivation season of Maha (October to March). The April to June rainfall coincides with the commencement of the subsidiary cultivation seasons of Yala (April to August) ${ }^{1}$. The rainfall peaks coincide with the passage of the Inter Tropical Convergence Zone (ITCZ) over the island ${ }^{10}$. Rainfall during these seasons is relatively high throughout the island.

b) Regionalization: The character of the annual climatology by region confirms that there are distinct rainfall characteristics for each region ${ }^{20}$. The Plains region may be divided between the Northern and Southern lobes. The Western and Eastern regions may be further divided into the coastal $(<150 \mathrm{~m})$ and hill $(>150 \mathrm{~m})$ regions as shown in Figure 1. This regionalization differs from the demarcation into dry, wet and intermediate zones which is based on the annual total rainfall and does not segregate the island into regions that distinguish the contrasting seasonality in different parts of Sri Lanka due to dominance by different rainfall mechanisms ${ }^{2,13}$. Accordingly, the "Plains" region includes the stations at Jaffna, Mannar,Anuradhapura, Puttalam and Hambantota. The "Eastern" region includes Trincomalee, Batticaloa, Ampara Tank, Badulla, Diyatalawa and Bandarawela (Diyatalawa and Bandarawela are considered as one station). The "Western" region includes Kurunegala, Katugastota, Nuwara Eliya, Colombo, Ratnapura and Galle.

c) Seasons: Up to the early $20^{\text {th }}$ century, meteorologists demarcated seasons as the Northeast monsoon (November to March) and Southwest monsoon (April to October). This demarcation was revised so as to introduce two additional intervening seasons termed "Inter-Monsoons"; since that period, the following seasons have been used in meteorological analysis: December to February, March to April, May to September, and October to November ${ }^{23}$. While, these are useful for analysis of some meteorological properties such as temperature and wind, they do not match well with the agricultural seasons of Maha (October to March) and Yala (April to August).

The consistent ENSO influences for October to December, January to March, April to June and July to August (ENSO influence is similar for a set of months) suggest a quarterly breakdown of seasons that correspond to the planting phase of (Maha:OctoberDecember, Yala:Aprl-June) and the harvesting phase of (Maha:January-March,Yala:July-August). Therefore, the ENSO influence by seasons starting in October is described here. In addition to these, May and July-August were taken into account since they correlate well with ENSO compared to corresponding quarter. 


\section{RESULTS}

The composite rainfall is computed by averaging the monthly rainfall values when the particular ENSO phase (El Niño, Neutral or La Niña) was prevalent.

\section{October to December (OND)}

The ENSO index shows a strong positive correlation with the OND rainfall in all regions at the $1 \%$ significant level (Table 2). Thus it is evident that El Niño conditions favor rainfall for the entirety of Sri Lanka during (October, November, December) (OND) season. During the 46 seasons in which the El Niño phase prevailed, 22 had rainfall above the normal tercile (Table 3 ). In the normal tercile, out of the 47 seasons El-Niño prevailed in 12 seasons while in 16, La Niña prevailed. Further during 46 seasons in which La Nina phase prevailed, in 24 seasons the rainfall is below the normal tercile. There is a slight drop of predictability in the Eastern Hills region that is subject to orographic rainfall. Based on these correlation values and the contingency table, the rainfall in early Maha has high predictability.

\section{January to March (JFM)}

Apart from the Eastern region, rainfall in all the other regions show significant correlations with ENSO (Table 2). While the overall correlation between NINO3 and rainfall for the entire record is modest, an examination of the annual climatology (Figure 2) shows that rainfall during El Niño phases is diminished in comparison to that during the La Nina phase. This relationship leads to low correlation values that mask the actual predictability. Of the 46 wettest tercile of seasons, 30 had neutral ENSO conditions (Table 3).

Table 1: The mean standard deviation (SD) and percentage of annual rainfall for quarterly and annual rainfall for all of Sri Lanka and for the three climatic regions are provided in mm. Details are provided for May (M) and July to August (JA) periods as well.

\begin{tabular}{lrrrrrrrr}
\hline Region & & JFM & AMJ & M & JAS & JA & OND & Total \\
\hline \multirow{2}{*}{ Sri Lanka } & Mean & 292 & 460 & 165 & 340 & 207 & 799 & 1891 \\
& & $15.40 \%$ & $24.30 \%$ & & $17.90 \%$ & & $42.20 \%$ & $100 \%$ \\
& SD & 127 & 101 & 76 & 95 & 67 & 184 & 217 \\
Plains & & & & & & & & \\
(Northern and & & $14.30 \%$ & $17.80 \%$ & & $8.40 \%$ & & $59.20 \%$ & $100 \%$ \\
Southern) & SD & 116 & 89 & 62 & 58 & 40 & 210 & 230 \\
Eastern & Mean & 374 & 233 & 84 & 227 & 133 & 848 & 1682 \\
& & $22.20 \%$ & $13.80 \%$ & & $13.50 \%$ & & $50.40 \%$ & $100 \%$ \\
& SD & 194 & 65 & 44 & 78 & 58 & 227 & 282 \\
Western & Mean & 319 & 764 & 276 & 563 & 356 & 827 & 2473 \\
& & $12.90 \%$ & $30.90 \%$ & & $22.80 \%$ & & $33.40 \%$ & $100 \%$ \\
& SD & 118 & 163 & 125 & 169 & 125 & 180 & 285 \\
\hline
\end{tabular}

Table 2: The correlation of rainfall with NINO3 from 1869 to 1998, for different regions and entire Sri Lanka. Correlation values that have significance levels for $1 \%$ and $5 \%$ are 0.22 and 0.17 and are shown in bold and italics respectively $(n=130)$.

\begin{tabular}{lrrrrr}
\hline Region & JFM & AMJ & M & JA & OND \\
\hline Northern Plains & $\mathbf{- 0 . 2 3}$ & $\mathbf{0 . 2 3}$ & $\mathbf{0 . 2 8}$ & $\mathbf{- 0 . 3 2}$ & $\mathbf{0 . 4 1}$ \\
Southern Plains & -0.17 & 0.2 & 0.17 & -0.1 & $\mathbf{0 . 4 1}$ \\
Eastern & -0.11 & 0.11 & $\mathbf{0 . 2 2}$ & $\mathbf{- 0 . 3 7}$ & $\mathbf{0 . 4 4}$ \\
Eastern Coast & -0.04 & 0.02 & 0.09 & $\mathbf{- 0 . 3}$ & $\mathbf{0 . 4}$ \\
Eastern Hills & -0.13 & 0.07 & $\mathbf{0 . 2 3}$ & $\mathbf{- 0 . 3 1}$ & $\mathbf{0 . 3 4}$ \\
Western & -0.2 & 0.18 & $\mathbf{0 . 2 5}$ & $\mathbf{- 0 . 1 9}$ & $\mathbf{0 . 4 6}$ \\
Western Coast & -0.18 & 0.16 & $\mathbf{0 . 2 2}$ & -0.04 & $\mathbf{0 . 4 5}$ \\
Western Hill & $\mathbf{- 0 . 1 7}$ & 0.18 & $\mathbf{0 . 2 3}$ & $\mathbf{- 0 . 2 6}$ & $\mathbf{0 . 4 8}$ \\
Sri Lanka & $\mathbf{- 0 . 1 8}$ & $\mathbf{0 . 2 2}$ & $\mathbf{0 . 2 9}$ & $\mathbf{- 0 . 2 9}$ & $\mathbf{0 . 5 1}$ \\
\hline
\end{tabular}


Table 3: The numbers of events in the three tercile categories -Wettest, Normal, Driest - that prevailed during El-Nino, La-Nina and Neutral events during different seasons

\begin{tabular}{llrrrr}
\hline Season & Tercile category & \multicolumn{4}{c}{ Number of events } \\
& & El-Nino & Neutral & La-Nina & Total \\
\hline \multirow{4}{*}{ OND } & Wettest & 22 & 14 & 10 & 46 \\
& Normal & 12 & 19 & 16 & 47 \\
& Driest & 6 & 16 & 24 & 46 \\
& Wettest & 6 & 30 & 10 & 46 \\
JFM & Normal & 12 & 23 & 12 & 47 \\
& Driest & 16 & 17 & 13 & 46 \\
& Wettest & 15 & 24 & 7 & 46 \\
\multirow{3}{*}{ AMJ } & Normal & 9 & 29 & 9 & 47 \\
& Driest & 11 & 29 & 6 & 46 \\
& Wettest & 21 & 15 & 10 & 46 \\
& Normal & 13 & 17 & 16 & 46 \\
& Driest & 6 & 16 & 24 & 46 \\
\multirow{3}{*}{ JA } & Wettest & 9 & 21 & 16 & 46 \\
& Normal & 12 & 18 & 17 & 47 \\
& Driest & 14 & 24 & 8 & 46 \\
\hline
\end{tabular}

Table 4: Comparison between predicted (Pre.) and actual (Act.) rain fall terciles below normal (BN), near normal (NN) and above normal (AN) along with the prevailing ENSO condition (EC) (El Nino-EN, Neutral-N, La Nina -LN)

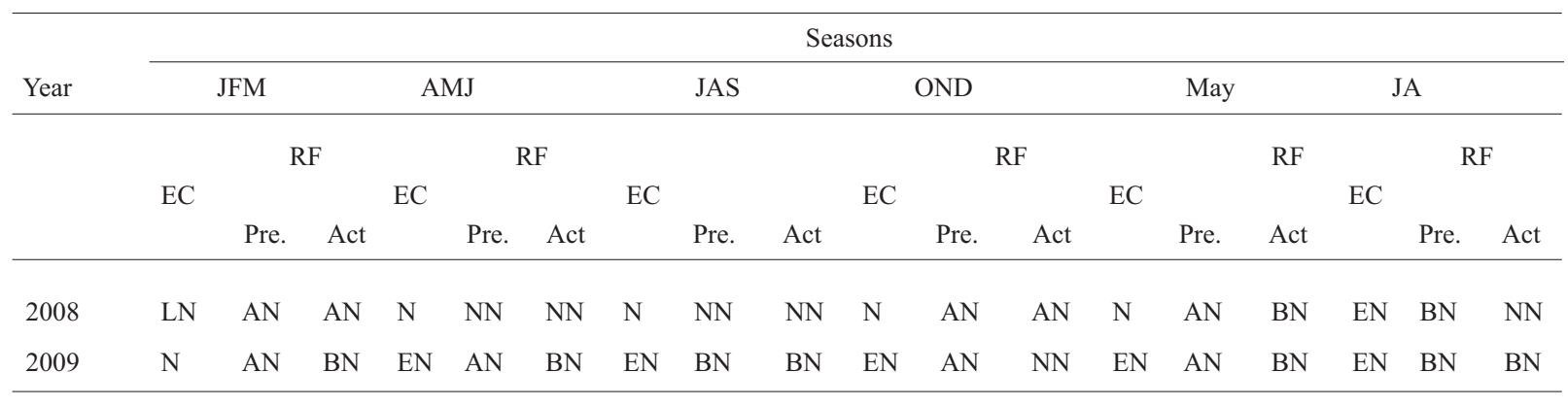

The decrease of predictability in the Eastern coast is likely due to cyclonic storms from the Bay of Bengal that reaches this coast.

\section{April to June (AMJ)}

Of the annual island-wide rainfall $24 \%$ occurs during this period (Table 1). The positive rainfall correlations with NINO3 indices are significant at the 5\% level except for the Eastern record (Table 2).

In the last three decades this correlation has dropped to insignificant levels due to a drop of the ENSO influence on the rainfall of April and June but not May (Table 2). Of the 46 seasons that account for the wettest tercile 15 were in the El Niño phase (Table 3). This is a small tilt of the odds due to ENSO. In contrast to the weak relationship between ENSO and rainfall during the April and June season, the May ENSO-rainfall correlation of all regions except Eastern coast has strengthened to 1\% significance level and southern plains to 5\%. Of the 46 seasons that account for the wettest tercile, 21 were in the El Niño phase (Table 3).

\section{July to August (JA)}

This is generally a dry period in the entire island except in the Southwest. During September South-Westerlies diminish. As September is a transitional month from a dry to a wet period and between periods of opposing ENSO influences, the rainfall in the latter half of September has characteristics akin to the October to December season and thus is omitted from this analysis. The July-August rainfall has a NINO3 correlation $(r=-0.29)$ that is highly significant for the entire island. Of the 46 seasons that account for the wettest tercile, 16 were in the $\mathrm{La}$ 
Niña phase as would be expected due to the negative correlations (Table 3). Similarly, of the 46 driest tercile seasons 14 were coincident with the El Niño phase.

\section{DISCUSSION}

The ENSO rainfall correlation during Yala (Jul-Aug) is greater outside the Western region and the Southern plains, which garners orographic rainfall in this season (Table 2). Orographic rainfall and cyclonic storms in Sri Lanka diminish the correlation between ENSO and rainfall. For instance, the Eastern region receives cyclonic storms from the Bay of Bengal and orographic rainfall from November to January: the ENSO correlations diminish for the Eastern region during January to March period. Similarly the Western region receives orographic rainfall when the westerlies are strongest during the period July to August and the ENSO correlations diminish in the Western region.

The predictability based on ENSO for rainfall is high from October to December. Even while the predictability of rainfall is modest for the period January to September, the accumulation of modest influence of ENSO over the period January to March and July to August leads to profound implications for various sectors. For example, there is reduction of stream flow for Yala during El Niño episodes $^{2}$. The rice cultivation in the Yala (April to August) season is significantly reduced during the El Niño period ${ }^{1}$. As the role of regional land surface and Indian Ocean sea surface conditions in modulating the climate is understood the prediction scheme presented here based on ENSO is likely to be improved.

A prediction scheme based on the seasonal ENSO index and the dominant precipitation tercile that is expected based on history up to 2007 was used to predict the precipitation for 2008 and 2009. A simple measure of skill based on the Heidke score shows that this prediction scheme scores 25 . This is a useful level of skill and comparable in skill to those for other ENSO-influenced areas such as Indonesia, Northeast Brazil and Eastern Africa $^{24}$.

\section{Acknowledgement}

Rainfall data were obtained from the Sri Lanka Department of Meteorology and from the Annual Reports submitted by the Colonial Administrators to Great Britain.

\section{References}

1. Zubair L. (2002). El-Niño -Southern Oscillation influences on rice production in Sri Lanka. International Journal of Climatology 22: 242-250.

2. Zubair L. (2003). Sensitivity of Kelani streamflow in Sri Lanka to ENSO. Hydrological Processes 17(12): 24392448.

3. Rasmusson E.M. \& Carpente T.H. (1983). The relationship between eastern equatorial Pacific sea surface temperature and rainfall over India and Sri Lanka. Monthly Weather Review 110: 354-384.

4. Ropelewski C.F. \& Halpert M.S. (1987). Global and regional scale precipitation patterns associated with the El Niño/Southern Oscillation. Monthly Weather Review 115: 1606-1626.

5. Suppiah R. (1997). Extremes of the southern oscillation phenomenon and the rainfall of Sri Lanka. International Journal of Climatology 17: 87-101.

6. Fernando T.K., Jayatillake Banda P.M. \& Chandrapala L. (1995). Recent ENSO events in Sri Lanka-a comparative study of the droughts of 1983, 1987 and 1992. Proceedings of the International Symposium on Climate and Life in the Asia Pacific, University of Brunei, Darussalam.

7. Punyawardena B.V.R. \& Cherry N.J. (1999). Assessment of the predictability of the seasonal rainfall in Ratnapura using Southern Oscillation and its two extremes. Journal of the National Science Council of Sri Lanka 27(3): 187195.

8. Sumathipala W.L. \& Punyadeva N.B.P. (1998). Variation of the rainfall of Sri Lanka in relation to El Niño. Proceedings of the Annual Sessions of the Institute of Physics, Sri Lanka, Colombo.

9. Suppiah R. (1989). Relationship between the southern oscillation and the rainfall of Sri Lanka. International Journal of Climatology 9: 601-618.

10. Suppiah R. (1996). Spatial and temporal variations in the relationships between the southern oscillation phenomenon and the rainfall of Sri Lanka. International Journal of Climatology 16: 1391-1407.

11. Kane R.P. (1998). ENSO relationships to the rainfall of Sri Lanka. International Journal of Climatology 18: 859871.

12. Malmgren B.A., Ranatunge E.R., Hayashi Y. \& Mikami T. (2003). Precipitation trends in Sri Lanka since 1870s and relationships to El Niño-Southern Oscillation. International Journal of Climatology 23(10): 1235-1252.

13. Zubair L. \& Ropelewski C.F. (2006). The strengthening relations between ENSO and North-East Monsoon rainfall over Southern India and Sri Lanka. Journal of Climate 19 (8): 1567-1575.

14. Domroes M. (1974). The Agroclimate of Sri Lanka. Franz Steiner Verlag Gmbh, Wiesbaden, Germany.

15. Yoshino M.M., Kayane I. \& Madduma Bandara C.M. 
(1983). Climate, Water and Agriculture in Sri Lanka. Institute of Geoscience, Climatological Notes 33 University of Tsukuba, Japan.

16. Peiris T.S.G., Hansen J. \& Zubair L. (2007). Use of seasonal climate information to predict coconut production in Sri Lanka. International Journal of Climatology 28(1): 103-110.

17. Chandimala J. \& Zubair L. (2007). ENSO based predictions for water resources management in Sri Lanka. Journal of hydrology 335: 303-312.

18. Goddard L., Mason S.J., Zebiak S.E., Ropelewski C.F., Basher R. \& Cane M.A. (2001). Current approaches to seasonal-to-interannual climate predictions. International Journal of Climatology 21(9): 1111-1152.

19. Press W.H., Teukolosky S.A., Vetterling W.T. \& Flannery B.P. (1992). Numerical Recipes in Fortran. Cambridge University Press, New York.

20. Puvaneswaram K.M. \& Smithson D.A. (1993). Controls on the precipitation distribution in Sri Lanka. Theoretical and Applied Climatology 47: 105-115.

21. Thambyahpillay G. (1954). The rainfall rhythm in Ceylon. University of Ceylon Review 12: 224-273.

22. Zubair L. (1999). A dynamical model for orographic rainfall in Sri Lanka. Proceedings of the National Symposium on Tropical Meteorology (TROPMET-99), Indian Meteorological Society, Chennai, India, 16-19 February 1999, pp. 269-273.

23. Bamford A.J. (1922). Ceylon rainfall. Quarterly Journal of the Royal Meteorological Society LXVIII (202): 206207.

24. Mason S.J., Goddard L., Graham N.E., Yulaeva E., Sun L. \& Arkin P. (1999). The IRI seasonal climate prediction system and the 1997/1998 El Nino Event. Bulletin of the American Meteorological Society 80(9):1853-1873.

25. Wilks D.S. (1995). Statistical Methods in Atmospheric Sciences. p. 467 Academic Press, San Diego, 467. California, USA. 